\title{
2 Cognitive and Contextual Variables in Sexual Partner 3 and Relationship Perception
}

\author{
4 Maria-João Alvarez • Leonel Garcia-Marques
}

Received: 3 October 2008 / Revised: 23 June 2010 / Accepted: 16 October 2010

(C) Springer Science+Business Media, LLC 2011

\begin{abstract}
This study examined the effects of contextual and cognitive variables for sexual protection on perceived social relationship factors. University students (108 women and 108 men) read script-based narratives on sexual encounters in which six variables were manipulated in two independent analyses. In the first analysis, four variables were evaluated: relational context (stable, casual), condom use (yes, no), script terminus (beginning, middle or end), and the rater's sex. The dependent variables were interpersonal perception of one of the characters of the narrative, and expectations regarding characteristics and future of the relationship. In the second analysis, two other factors were manipulated only in the "yes" condom conditions: communication strategy (verbal, non-verbal) and condom proponent gender. Our findings corroborated other studies where condom use was viewed as unromantic with less positive characteristics for relationships. Condom proponents, especially male, were perceived as less romantic, particularly when proposing a condom non-verbally at the beginning of the encounter. However, the controlled variables enabled us to propose ways of associating condom use with positive expectations towards the proponent and the relationship itself. Romanticism, expectation of sexual intercourse, emotional proximity, and expectations of condom use in encounters where a condom was proposed increased when suggested by a woman, postponed to the end of the encounter, and verbally mentioned. We encourage women to take the lead in suggesting condom use, thus empowering them since they do not have to wait for the male to make the first move.
\end{abstract}

\section{M.-J. Alvarez $(\bowtie) \cdot$ L. Garcia-Marques}

Faculty of Psychology, University of Lisbon, Alameda da

Universidade, 1649-013 Lisbon, Portugal

e-mail: mjalvarez@fp.ul.pt
Keywords Condom use - Interpersonal perception . HIV/AIDS prevention · Gender · Relationship expectations

\section{Introduction}

New interpersonal and situational variables (e.g., Bryan, Aiken, \&West, 1999; Flowers, Smith, Sheeran, \& Beail, 1997) and less deliberate and more automatic processes (e.g., Miller, Bettencourt, DeBro, \& Hoffman, 1993; Williams et al., 1992) have recently been explored with a view to understanding sexual protection behavior. By means of underlying knowledge structures, the role of interpersonal perception may be identified among the variables involved in these processes and capable of influencing and predicting individual behavior (Galambos, Abelson, \& Black, 1986).

The representation of types of people with whom we can interact is an important social structure. In other words, we organize information regarding individual personality through a trait network associated with specific behavior or personality content, enabling us to predict and understand their reactions. There seem to be naïve or implicit personality theories at the root of impression formation on how these characteristics are organized (Bruner \& Tagiuri, 1954; Schneider, 1973). Social judgment and personality trait inference are also triggered by contraceptive-related behavior, particularly condom use (Bryan et al., 1999; McKinney, Sprecher, \& Orbuch, 1987).

Interpersonal perception phenomena involved in condom use may be distinguished by two main processes: one related to inferences on the probability of partner infection and respective evaluation of the need for condom use (Civic, 1999; Misovich, Fisher, \& Fisher, 1996, 1997; Williams et al., 1992); the other is related to the image projected of oneself or of the partner, as well as expectations for the future of the relationship when such sexual protection is used (Bryan et al., 1999; Hammer, Fisher,

$\begin{array}{lll}\text { Journal : Large 10508 } & \text { Dispatch : 8-1-2011 } & \text { Pages : } \mathbf{1 1} \\ \text { Article No. : } \mathbf{9 7 2 5} & \square \text { LE } & \square \text { TYPESET } \\ \text { MS Code : ALVAREZ_1-3 } & \sim_{\text {CP }} & \checkmark \text { DISK }\end{array}$


Fitzgerald, \& Fisher, 1996; Hynie \& Lydon, 1995). In this dynamic, protection is also affected by one partner's ability to involve the other in condom use (e.g., Cline, Johnson, \& Freeman, 1992) as well as the perception of how suitable the proposal is to the proponent's gender (Hynie \& Lydon, 1995; Sacco, Rickman, Thompson, Levine, \& Reed, 1993).

People believe themselves to be capable of recognizing a partner who is not infected with HIV/AIDS on the basis of nondiagnostic characteristics, ranging from physical appearance to personality traits and relationship status. They stereotype the HIV carrier and believe that the person can be distinguished quite easily (e.g., Maticka-Tyndale, 1991; Williams et al., 1992). It is equally frequent for partners who know each other, bearing specific personality characteristics such as amiability and courteousness, to be considered safer, hence arousing less preoccupation with sexual contact (e.g., Maticka-Tyndale, 1991). Indeed, relational influences may be displayed before any type of relationship has been established through the use of implicit personality theories which stereotype the prototype of the HIV/AIDS carrier and replace consistent condom use (Williams et al., 1992).

The positive feelings developed by the partner and the duration of the relationship also influence the perceived need for safe sexual practices. Thus, partners in a stable relationshipeven when there is limited commitment-are perceived as presenting less of a risk of infection than those in a casual relationship (Misovich et al., 1996, 1997). Since affection seems to represent a barrier against infection, the perception of danger and disease is mainly associated with casual relationships. Consequently, people tend to interpret unprotected sexual intercourse as being more special and romantic (e.g., Conley \& Rabinowitz, 2004; Flowers et al., 1997; Galligan \& Terry, 1993) whereas condom use may even be viewed as a risk to the potential development of a more stable romantic relationship (e.g., Rosenthal, Gifford, \& Moore, 1998).

Indeed, condoms are rarely regarded as being attractive or conducive to intimacy and sexual pleasure or as transmitters of trust or spontaneity between partners (Hammer et al., 1996; Sacco et al., 1993). Although the overall impression formed by contraceptive users following protective behavior is favorable, and they are seen to be more intelligent and mature (McKinney et al., 1987), a more ambiguous stance is adopted towards condom proponents who are also considered less romantic and exciting than non-proponents (Bryan et al., 1999). Women regard female condom proposal as having low social acceptability and being conducive to the development of a negative image from the partner's perspective (Hynie \& Lydon, 1995). Men believe that condom use reduces the probability of sexual intercourse (Bryan et al., 1999). Thus, there are also beliefs associated with condom use grounded in fear of its negative implications.

Condom use in an encounter where protection is perceived as important will depend on the communication skills between partners. Such negotiation often proves to be difficult. Non-verbal condom introduction may act as a strategy to facilitate sexual communication since it is seen to be more suitable to the type of interaction developed during sexual exchange (Miller et al., 1993) and keeps unsafe sex at bay. Nevertheless, female perception of male condom proponent is seen to be more positive when the proposal is verbal (Bryan et al., 1999). In addition to the employed strategy, the point at which the condom is introduced or referred to also seems to contribute to the use of protection. The condom is usually discussed between heterosexuals when sexual intercourse is imminent (e.g., Cline et al., 1992; Edgar \& Fitzpatrick, 1993).

Aims of the Present Study

This study set out to ascertain whether condom use provides information on the personality of the proponent and on the characteristics and future of the relationship. Condom use was analyzed by considering the extent to which the relational context, the script terminus, the communication strategy used for condom proposal, and proponent gender provide information on the personality of the proponent and relationship expectations through a vignette-analogue study. The presentation of information to participants (perceivers) about an individual (a target) in the form of written vignettes as stimulus material is a traditional method in the study of person perception (Hamilton, 1986). We extended its use to perception of the characteristics and future development of the relationship. The use of vignettes to study the effect of sexual protection on the perception of its proponent and the outcomes of sexual encounters have enabled the collection of consistent information and contributed to the prediction of protective behavior in individuals (e.g., Bryan et al., 1999; Hynie \& Lydon, 1995; McKinney et al., 1987). We tried to broaden the aims of other studies by assessing the effect of condom introduction in different settings (stable and casual relationship encounters), instead of restricting our analysis to the first sexual encounter, as is usually the case. Finally, instead of solely evaluating differences in men and women towards male proponents, condom proponents from both sexes were used.

Hypothesis 1 It was predicted that partners would be expected to be more positively evaluated, i.e., as more romantic and responsible, in a more serious relationship context than in a casual relationship, given the feelings of affection between partners and the trust and confidence developed in longer relationships (Misovich et al., 1996, 1997).

Hypothesis 2 It was predicted that condom proponents would be perceived as being more responsible and mature and less romantic and exciting in comparison with non-users, since, in the perception of the partner, condom use is associated with greater maturity and responsibility and less romanticism and excitement (Bryan et al., 1999; McKinney et al., 1987). 
Hypothesis 3 It was predicted that the woman condom proponent would also be perceived as being less romantic and responsible in comparison with the man proponent. Such anticipation is the result of social expectations as to the purchase, possession, and use of the condom, particularly on the part of women (Hynie \& Lydon, 1995; Sacco et al., 1993).

Hypothesis 4 It was predicted that a less intrusive script terminus for condom introduction would coincide with the imminence of sexual intercourse. This expectation results from the fear, mainly on the part of men, that reference to condom use may render sexual intercourse unfeasible (Bryan et al., 1999) and from the practice of including the condom very close to the point of sexual intercourse between heterosexual individuals (e.g., Edgar \& Fitzpatrick, 1993).

Hypothesis 5 It was predicted that more positive expectations regarding the characteristics and future of the relationship would be revealed in encounters where the condom is not used. This expectation stems from the inference of greater romanticism and affection between partners in relationships where the condom is not used (Galligan \& Terry, 1993; Rosenthal et al., 1998) and from the belief, on the part of men, that condom use reduces the probability of sexual intercourse (Bryan et al., 1999).

Hypothesis 6 Finally, it was expected that the condom would be used less in a stable relationship than in a casual one, given the importance of the relational context in the partner's perception of safety and the respective need for protection (Misovich et al., 1996, 1997).

As for the strategy of communication used in condom use proposal, the rather disparate conclusions of prior studies did not provide sufficient information to determine whether there is preference for one type of communication over another.

\section{Method}

\section{Participants}

A total of 216 Portuguese university students (108 men, 108 women) with a mean age of 21.19 years $(S D=1.96)$ were recruited between March and May 2000, from ten different courses, with faculty authorization. ${ }^{1}$ Participants were requested to participate in a psychology research study and those willing to participate provided voluntary, informed consent and

1FL01 ${ }^{1}$ Communication Sciences, Philosophy, Geography, History, Man1FL02 agement, International Relations, Psychology, Education, Mechanical 1FL03 Engineering, and Computer Sciences from three universities in the 1FL04 Lisbon region. were informed that they could discontinue their participation at any time. The refusal rate was very low $(.9 \%)$.

The Portuguese university student population is characterized by approximately half of the women and $80 \%$ of the men having already had sexual intercourse. More than half are in a relationship and have sexual intercourse, on average, six times per month. Around $25 \%$ of men and $5 \%$ of women refer to having more than one simultaneous partner. Sexual practice with individuals of the same sex is mentioned by approximately $2 \%$ of women and $5 \%$ of men. Condom use is rarely mentioned by more than $40 \%$ of individuals and its use is not systematic (Alferes, 1997; Alvarez, 2005).

Measures

\section{Independent Variables: Sexual Encounters}

The study used descriptions of sexual interactions considered typical by university students for stable and casual encounters (Alvarez \& Garcia-Marques, 2008). In the first analysis, three conditions - relational context (stable vs. casual), condom use (yes vs. no) and script terminus (beginning, middle, or end), plus sex of the rater-were manipulated in a $2 \times 2 \times 3 \times 2$ between-subjects design. In the second analysis, for participants in the condom "yes" condition, we manipulated two additional variables: communication strategy in condom use introduction (verbal vs. non-verbal) and condom proponent's gender (man vs. woman), in a 2 (relational context) $\times 3$ (script terminus) $\times 2$ (communication strategy) $\times 2$ (proponent $) \times 2$ (sex rater) design.

In the vignette description of the stable relationship encounter, both characters had been in the relationship for a short period of time and had never had sexual intercourse. Therefore, condom reference could not be interpreted as the result of a routine. It had to be taken in the context of an initial negotiation between partners, an essential condition for comparing both types of encounter.

An example of the experimental condition of a stable relationship, where condoms are used with a verbal communication strategy up to the end of the script, with a man proponent is as follows: Carlos and Ana, who have been in a stable relationship around a month and have never had sexual intercourse with each other, decide to meet up on this particular day. They talk about various subjects, trivial things, during a walk. At a certain moment, they look into each other's eyes. They smile and move closer to each other. Inside the car/, he takes her hand, strokes her hair, and they caress each other/. They kiss each other. They look at each other and kiss again. Once at home, they lie down and fondle each other. They remove the upper part of each other's clothing. Their hearts start to beat faster. They continue to kiss and caress each other. They remove some more articles of clothing. They get completely 
undressed as they continue to exchange caresses. He says he prefers using a condom. ${ }^{2}$

In the non-verbal communication strategy, "she takes a condom out of her handbag and passes it to him" (in the case of a woman proponent) and "he takes a condom out of his pocket and passes it to her" (for a man proponent). When the condom is not mentioned, the encounter ends with an ellipsis (...). Slashes are introduced in the script examples to pinpoint the beginning and middle conditions where the narrative was discontinued due to manipulation of the script terminus.

\section{Dependent Variables}

Two dependent variables were analyzed, one related to the interpersonal perception of one of the characters of the vignette and the other related to expectations regarding characteristics and future of the relationship.

Interpersonal perception was evaluated by a set of 13 adjectives: romantic, affectionate (which define the romantic factor), mature, responsible (mature factor), sincere, respectful (nice factor), spontaneous, adventurous (exciting factor), promiscuous (promiscuous factor), kind, amiable, attractive, and trustworthy. The first nine adjectives, which defined the five factors (in brackets), stemmed from a research study in which suitable adjectives for sexual partners were collected (Bryan et al., 1999). Two characteristics (kindness and amiability), habitually present in implicit personality theories (Rosenberg \& Sedlak, 1972) and pertinent to the evaluation of a potential sexual partner, were also introduced in the study. A further two characteristics taken from the evaluation of a sexual partner, namely attraction and trustworthiness, were also introduced (Hammer et al., 1996). The adjectives were presented randomly and evaluated with a 15-point semantic differential (e.g., matureimmature). This scale was anchored on -7 to +7 bounds.

Expectations regarding the characteristics and future of the relationship were evaluated through the presence of emotional proximity ("there is emotional proximity between them"), the future of the relationship ("the relationship will continue"), the consummation of sexual intercourse ("they will have sexual intercourse during this encounter"), condom use ("the condom will be used during this encounter"), and the existence of a sexually transmitted infection (STIs), including HIV ("Carlos [Ana] is infected with a sexually transmitted disease (other than HIV)", "Carlos [Ana] is HIV positive"), by means of a six-point probability scale ranging from highly improbable (1) to highly probable (6).

Expectations regarding emotional proximity, continuation of the relationship, and consummation of sexual intercourse were viewed as positive expectations, whereas the existence of STIs, including HIV, was considered negative. No value was attributed to condom use.

\footnotetext{
2 An example of the same experimental condition for casual relationship is presented in the Appendix.
}

Procedure

Data were collected in the classroom with variable sized groups, but never with less than 20 persons and randomly distributed by conditions. Our instructions indicated that we were interested in studying the impressions they had formed of each other and participants were asked to put themselves in the position of one of the characters (Carlos or Ana) and to evaluate the situation as he or she would.

Description of the sexual encounter was presented after the instructions, followed by the adjectives characterizing the participant's perception of what one of the characters (the nonproponent) had thought in relation to the other partner in the story. This was followed by questions on the likelihood of certain expectations of the characteristics and future of the relationship being accomplished.

Each participant responded to only one of the conditions. Six participants (three women and three men) responded to each condition, except in conditions without condom introduction where the number of participants doubled (six women and six men). To be more precise, in conditions including the condom, the (proponent) characters were evaluated by six women and six men, the proponent man by three women and three men, and the proponent woman by a further three women and three men; thus, there were six participants per condition. In conditions excluding the condom, six women and six men were requested to participate in each condition in order to have an equal number of answers for each gender character. Half evaluated the male character and the other half the female character.

Statistical Analysis

The aforementioned 13 adjectives served as the basis for evaluating the effect of cognitive and contextual variables on the interpersonal perception of sexual partners. To ensure clear understanding of potential relations, these items underwent a factor analysis with orthogonal rotation. The internal consistency of the factors was estimated by Cronbach's alpha. Factor scores were obtained with the regression method from the factor score coefficients and the matrix of the standardized data waves.

For interpersonal perception, univariate analysis of variance (ANOVA) was used in order to explore the variables susceptible to differentiate experimental groups.

For expectations regarding the characteristics and future of the relationship, multivariate analysis of variance (MANOVA) was used and the significant results were later interpreted on the basis of a discriminant analysis and explored through an ANOVA. Significant univariates $F$ and discriminant analysis standardized coefficients above .40 (to highlight only the most important results) and non-significant univariate $F_{\mathrm{S}}$ with standardized coefficients above the considered criteria were interpreted in accordance with the guidelines laid down by Applebaum and McCall (1983).

$\begin{array}{lll}\text { Journal : Large 10508 } & \text { Dispatch : 8-1-2011 } & \text { Pages : 11 } \\ \text { Article No. : } \mathbf{9 7 2 5} & \square \text { LE } & \square \text { TYPESET } \\ \text { MS Code : ALVAREZ_1-3 } & \checkmark_{\text {CP }} & \checkmark \text { DISK }\end{array}$




\section{Results}

\section{Interpersonal Perception}

Examination of the eigenvalues and scree plot indicated that two factors could be extracted (Table 1), and a total of 13 adjectives were retained, 8 for Factor 1 and 7 for Factor 2. Judging from the items that had factor loadings higher than .45 in each of the two factors, the first was labeled Romanticism (Cronbach's alpha = .83 , accounting for $30.8 \%$ of the total variance) and the second was labeled Responsibility (Cronbach's alpha $=.72$, accounting for $17.6 \%$ of the total variance).

\section{Romanticism}

Table 2 shows the mean ratings and $S D$ s of romanticism and responsibility perceived in a potential sexual partner as a function of the main effects and significant interactions of relational context, condom use, script terminus, and rater's sex (first analysis).

In terms of romanticism, the ANOVA of this first analysis showed a significant interaction between condom and script terminus, $F(2,177)=4.43, p=.013, \eta_{\mathrm{p}}^{2}=.05$. When the condom was referred to in the encounters, the partners were perceived as less romantic and the difference in romanticism between condom use and non-use was greater at the beginning of the encounter than the same difference halfway through and at the end of the encounter.

Table 3 shows the mean ratings and $S D$ s of romanticism and responsibility perceived in a potential sexual partner as a function of the main effects and significant interactions of relational

Table 1 Factor loadings for principal component analysis with varimax rotation of 13 trait adjectives for interpersonal perception of a potential sexual partner

\begin{tabular}{lll}
\hline Adjectives & $\begin{array}{l}\text { Factor } 1 \\
\text { Romanticism }\end{array}$ & $\begin{array}{l}\text { Factor } 2 \\
\text { Responsibility }\end{array}$ \\
\hline Affectionate & $\mathbf{. 7 4}$ & .14 \\
Amiable & $\mathbf{7 4}$ & .19 \\
Kind & $\mathbf{. 7 3}$ & .06 \\
Attractive & $\mathbf{. 7 2}$ & -.10 \\
Romantic & $\mathbf{. 6 1}$ & .29 \\
Spontaneous & $\mathbf{. 5 6}$ & -.27 \\
Responsible & -.16 & $\mathbf{. 7 5}$ \\
Unadventurous & -.33 & $\mathbf{. 6 8}$ \\
Mature & .20 & $\mathbf{. 5 9}$ \\
Sincere & .05 & $\mathbf{. 5 4}$ \\
Non-Promiscuous & .23 & $\mathbf{. 4 6}$ \\
Respectful & $\mathbf{. 5 2}$ & $\mathbf{. 5 6}$ \\
Trustworthy & $\mathbf{. 5 2}$ & $\mathbf{. 5 3}$ \\
\hline
\end{tabular}

Note: In boldface are highlighted factor loadings ( $>.45)$ that contribute most to the factor
Table 2 Mean scores and $S D$ s for main effects and significant interactions for romanticism and responsibility perceived in a potential sexual partner (first analysis)

\begin{tabular}{|c|c|c|c|}
\hline Controlled variables & $n$ & $\begin{array}{l}\text { Romanticism }{ }^{\mathrm{a}} \\
M^{\mathrm{c}}(S D)\end{array}$ & $\begin{array}{l}\text { Responsibility } \\
M^{\mathrm{c}}(S D)\end{array}$ \\
\hline \multicolumn{4}{|l|}{ Relational context } \\
\hline Stable & 102 & $-.10(.98)$ & $.30(.87)$ \\
\hline Casual & 99 & $.10(1.01)$ & $-.31(1.03)$ \\
\hline \multicolumn{4}{|l|}{ Condom use (C) } \\
\hline Yes & 136 & $-.28(1.00)$ & $.15(1.02)$ \\
\hline No & 65 & $.58(.70)$ & $-.32(.87)$ \\
\hline \multicolumn{4}{|l|}{ Script terminus (ST) } \\
\hline Beginning & 68 & $-.36(1.19)$ & $-.08(1.00)$ \\
\hline Middle & 71 & $.12(.82)$ & $.01(1.09)$ \\
\hline End & 62 & $.25(.85)$ & $.08(.90)$ \\
\hline \multicolumn{4}{|l|}{ Sex of rater } \\
\hline Woman & & $.02(1.09)$ & $.08(1.06)$ \\
\hline Man & & $-.02(.91)$ & $-.08(.94)$ \\
\hline \multicolumn{4}{|l|}{$\mathrm{C} \times \mathrm{ST}$} \\
\hline Yes beginning & 44 & $-.86(1.10)$ & $-.10(1.08)$ \\
\hline Yes middle & 48 & $-.09(.78)$ & $.34(1.00)$ \\
\hline Yes end & 44 & $.10(.87)$ & $.21(.97)$ \\
\hline No beginning & 24 & $.56(.71)$ & $-.05(.85)$ \\
\hline No middle & 23 & $.56(.73)$ & $-.68(.97)$ \\
\hline No end & 18 & $.64(.68)$ & $-.21(.61)$ \\
\hline
\end{tabular}

${ }^{a}$ Absolute range for Romanticism: $\min .=-3.29, \max .=2.31$

b Absolute range for Responsibility: $\min .=-2.5$, $\max .=2.26$

c Values are the means of the factor scores

)

context, communication strategy, script terminus, proponent gender, and rater's sex (second analysis).

In this second analysis, for romanticism, we found a significant interaction between the communication strategy, the script terminus, and the proponent's gender, $F(2,88)=5.53, p=.005$, $\eta_{\mathrm{p}}^{2}=.11$, which enabled us to specify that the less romantic perception of the man, in comparison with the woman, was heightened when the condom was used non-verbally at the beginning of an encounter and was inverted halfway through the encounter when words were used to introduce the condom (Fig. 1).

A significant interaction found between script terminus and proponent's gender, $F(2,88)=6.82, p=.002, \eta_{\mathrm{p}}^{2}=.13$, led to the finding that the less romantic condom proponent was the man and the difference in proponent romanticism was higher when the condom was introduced at the beginning than in the middle or at the end of the encounter.

Responsibility

In terms of responsibility, the first analysis showed a significant main effect of the relational context, $F(1,177)=20.84$,
403 404

$\begin{array}{lll}\text { Journal : Large 10508 } & \text { Dispatch : 8-1-2011 } & \text { Pages : } \mathbf{1 1} \\ \text { Article No. : } 9725 & \square \text { LE } & \square \text { TYPESET } \\ \text { MS Code : ALVAREZ_1-3 } & \square_{\text {CP }} & \checkmark \text { DISK }\end{array}$


Table 3 Mean scores and SDs for main effects and significant interactions for romanticism and responsibility perceived in a potential sexual partner (second analysis)

\begin{tabular}{|c|c|c|c|}
\hline Controlled variables & $n$ & $\begin{array}{l}\text { Romanticism }{ }^{\mathrm{a}} \\
M^{\mathrm{c}}(S D)\end{array}$ & $\begin{array}{l}\text { Responsibility } \\
M^{\mathrm{C}}(S D)\end{array}$ \\
\hline \multicolumn{4}{|l|}{ Relational context } \\
\hline Stable & 69 & $-.36(1.02)$ & $.44(.94)$ \\
\hline Casual & 67 & $.20(.99)$ & $-.14(1.03)$ \\
\hline \multicolumn{4}{|c|}{ Communication strategy (CS) } \\
\hline Verbal & 67 & $-.27(.91)$ & $.30(1.10)$ \\
\hline Non-verbal & 69 & $-.29(1.09)$ & $.01(.93)$ \\
\hline \multicolumn{4}{|l|}{ Script terminus (ST) } \\
\hline Beginning & 44 & $-.86(1.10)$ & $-.10(1.08)$ \\
\hline Middle & 48 & $-09(.78)$ & $.34(.99)$ \\
\hline End & 44 & $.10(.87)$ & $.21(.97)$ \\
\hline \multicolumn{4}{|l|}{ Proponent (P) } \\
\hline Woman & 69 & $-.05(.88)$ & $.14(1.04)$ \\
\hline Man & 67 & $-.52(1.07)$ & $.17(1.02)$ \\
\hline \multicolumn{4}{|l|}{ Sex of rater } \\
\hline Woman & 70 & $-.28(1.10)$ & $.26(1.07)$ \\
\hline Man & 66 & $-.28(.90)$ & $.04(.97)$ \\
\hline \multicolumn{4}{|l|}{$\mathrm{CS} \times \mathrm{P}$} \\
\hline Verbal woman & 35 & $-.12(.91)$ & $.11(1.15)$ \\
\hline Verbal man & 32 & $-.43(.90)$ & $.51(1.02)$ \\
\hline Non-verbal woman & 34 & $.02(.87)$ & $.17(.93)$ \\
\hline Non-verbal man & 35 & $-.59(1.21)$ & $-.15(.91)$ \\
\hline \multicolumn{4}{|l|}{$\mathrm{ST} \times \mathrm{P}$} \\
\hline Beginning woman & 22 & $-.20(.84)$ & $.07(1.09)$ \\
\hline Beginning man & 22 & $-1.53(.92)$ & $-.27(1.07)$ \\
\hline Middle woman & 24 & $-.15(.79)$ & $.40(1.05)$ \\
\hline Middle man & 24 & $-.02(.78)$ & $.28(.95)$ \\
\hline End woman & 23 & $.20(1.00)$ & \\
\hline End man & 21 & $-.02(.70)$ & $.50(.90)$ \\
\hline
\end{tabular}

$\mathrm{CS} \times \mathrm{ST} \times \mathrm{P}$ is a significant interaction and it is shown in Fig. 1 for better understanding of the interaction

a Absolute range for Romanticism: min. $=-3.29, \max .=2.31$

b Absolute range for Responsibility: $\min .=-2.5$, max. $=2.26$

c Values are the means of the factor scores

$p<.001, \eta_{\mathrm{p}}^{2}=.11$. Partners were perceived as being more responsible in a stable relationship than in a casual one. A significant interaction was also found between condom use and script terminus, $F(2,177)=5.31, p=.006, \eta_{\mathrm{p}}^{2}=.06$. When the condom was present, the partners were regarded as more responsible and its introduction at the beginning of the encounter did not alter the perception of responsibility, which was higher when it was introduced in the middle or at the end of the encounter (Table 2).

In the second analysis, for responsibility, we found the same significant effect of the relational context, $F(1,88)=11.42$, $p=.001, \eta_{\mathrm{p}}^{2}=.12$, as verified in the first analysis. It revealed a significant interaction between communication strategy and proponent, $F(1,88)=4.59, p=.04, \eta_{\mathrm{p}}^{2}=.05$, and the difference in responsibility between using a verbal and non-verbal strategy for condom use proposal was greater when the proponent was a man than when the proponent was a woman (Table 3).

Expectations Regarding the Characteristics and Future of the Relationship

The multivariate analyses revealed a set of variables and some interactions bearing an effect on expectations regarding the characteristics and future of the relationship. In the first analysis, the MANOVA revealed statistically significant effects of the relational context, $\Lambda=.63, F(6,186)=18.33, p<.001, \eta_{\mathrm{p}}^{2}=$ .37 , condom use, $\Lambda=.89, F(6,186)=3.70, p=.002, \eta_{\mathrm{p}}^{2}=.12$, script terminus $\Lambda=.76, F(12,372)=4.59, p<.001, \eta_{\mathrm{p}}^{2}=.13$, sex of the rater, $\Lambda=.93, F(6,186)=2.27, p=.039, \eta_{\mathrm{p}}^{2}=.07$, and an interaction between condom use and script terminus, $\Lambda=.87, F(12,372)=2.31, p=.007, \eta_{\mathrm{p}}^{2}=.07$, on characteristics and future of the relationship.

Table 4 shows the mean ratings and SDs of the characteristics and future of the relationship as a function of the main effects and significant interactions of relational context, condom use, script terminus, and rater's sex (first analysis).

Univariate analyses showed a significant main effect of the relational context on emotional proximity, $F(1,191)=54.79$, $p<.001, \eta_{\mathrm{p}}^{2}=.22$, which was higher in stable relationships than in casual ones. Emotional proximity was also affected by a significant interaction between condom use and script terminus, $F(2,191)=3.79, p=.02, \eta_{\mathrm{p}}^{2}=.04$, which was greater when the partner did not use a condom, and the difference between condom use and non-use was higher at the end of the encounter than the same difference at the beginning and halfway through the encounter. Only the relational context contributed to the expectation that the relationship would continue, $F(1,191)=78.27$, $p<.001, \eta_{\mathrm{p}}^{2}=.29$, which was associated with a stable relationship. The inferred probability of sexual relationships was affected by script terminus, $F(2,191)=14.14, p<.001, \eta_{\mathrm{p}}^{2}=$ .13 , as condom introduction in the middle or at the end of a sexual encounter increased the expectation of sexual intercourse. It was also affected by the sex of the rater, $F(1,191)=$ $5.44, p=.02, \eta_{\mathrm{p}}^{2}=.03$, as men had higher expectations that the encounter would lead to sexual intercourse than women. The condom affected expectation of its use, whereby condom reference in the encounter increased the perception of it being used, $F(1,191)=10.15, p=.002, \eta_{\mathrm{p}}^{2}=.05$. Finally, sex of the rater affected STI expectations, and women associated condom proposal with the presence of an STI more than men, $F(1,191)=$ $6.39, p=.01, \eta_{\mathrm{p}}^{2}=.03$ (Table 4).

In the second analysis, the MANOVA revealed statistically significant effects of the relational context, $\Lambda=.55, F(6,90)=$ $12.08, p<.001, \eta_{\mathrm{p}}^{2}=.45$, script terminus, $\Lambda=.65, F(12,180)=$ $3.64, p<.001, \eta_{\mathrm{p}}^{2}=.20$, proponent, $\Lambda=.67, F(6,90)=7.51$,

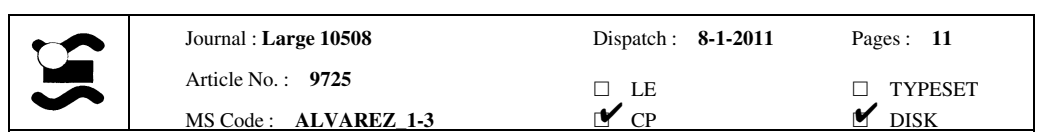


Fig. 1 Interaction among communication strategy for condom use, script terminus, and proponent in perceived romanticism

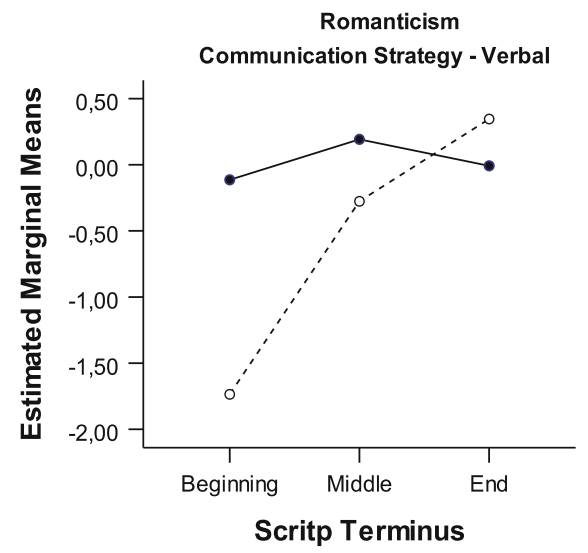

Table 4 Mean scores and $S D$ s for main effects and significant interactions for characteristics and future of the relationship (first analysis)

\begin{tabular}{|c|c|c|c|c|c|c|c|}
\hline Controlled variables & $n$ & $\begin{array}{l}\text { Emotional proximity } \\
M(S D)\end{array}$ & $\begin{array}{l}\text { Relationship } \\
\text { continuation }^{\text {a }} \\
M(S D)\end{array}$ & $\begin{array}{l}\text { Sexual relations }{ }^{\mathrm{a}} \\
M(S D)\end{array}$ & $\begin{array}{l}\text { Condom use } \\
M(S D)\end{array}$ & $\begin{array}{l}\mathrm{STI}^{\mathrm{a}} \\
M(S D)\end{array}$ & $\begin{array}{l}\mathrm{HIV}^{\mathrm{a}} \\
M(S D)\end{array}$ \\
\hline \multicolumn{8}{|l|}{ Relational context } \\
\hline Stable & 108 & $4.80(.90)$ & $4.41(.91)$ & $4.62(1.24)$ & $4.83(1.25)$ & $2.77(1.02)$ & $2.64(1.16)$ \\
\hline Casual & 108 & $3.67(1.27)$ & $3.18(1.00)$ & $4.65(1.54)$ & $4.96(1.25)$ & $2.81(1.10)$ & $2.72(1.13)$ \\
\hline \multicolumn{8}{|l|}{ Condom use (C) } \\
\hline Yes & 144 & $4.11(1.27)$ & $3.77(1.15)$ & $4.63(1.45)$ & $5.08(1.26)$ & $2.88(1.03)$ & $2.77(1.10)$ \\
\hline No & 72 & $4.49(1.13)$ & $3.83(1.11)$ & $4.64(1.28)$ & $4.54(1.14)$ & $2.60(1.10)$ & $2.50(1.21)$ \\
\hline \multicolumn{8}{|l|}{ Script terminus (ST) } \\
\hline Beginning & 72 & $4.10(1.13)$ & $3.74(1.02)$ & $3.89(1.52)$ & $4.72(1.42)$ & $2.85(1.06)$ & $2.85(1.15)$ \\
\hline Middle & 72 & $4.14(1.20)$ & $3.88(1.20)$ & $5.04(1.05)$ & $5.14(.92)$ & $2.69(1.08)$ & $2.44(1.03)$ \\
\hline End & 72 & $4.50(1.34)$ & $3.76(1.19)$ & $4.97(1.27)$ & $4.83(1.32)$ & $2.82(1.04)$ & $2.75(1.22)$ \\
\hline \multicolumn{8}{|l|}{ Sex rater } \\
\hline Woman & 108 & $4.22(1.27)$ & $3.80(1.07)$ & $4.41(1.53)$ & $4.81(1.28)$ & $2.97(1.07)$ & $2.85(1.10)$ \\
\hline Man & 108 & $4.26(1.20)$ & $3.79(1.20)$ & $4.86(1.20)$ & $5.00(1.21)$ & $2.60(1,01)$ & $2.51(1.16)$ \\
\hline \multicolumn{8}{|l|}{$\mathrm{C} \times \mathrm{ST}$} \\
\hline Yes begin & 48 & $3.88(1.18)$ & $3.65(1.04)$ & $3.83(1.72)$ & $4.69(1.57)$ & $2.92(1.00)$ & $2.90(1.13)$ \\
\hline Yes middle & 47 & $4.21(1.16)$ & $4.02(1.10)$ & $5.02(.96)$ & $5.35(.85)$ & $2.85(1.08)$ & $2.69(.99)$ \\
\hline Yes end & 48 & $4.25(1.45)$ & $3.65(1.28)$ & $5.04(1.25)$ & $5.19(1.18)$ & $2.88(1.02)$ & $2.73(1.18)$ \\
\hline No begin & 24 & $4.46(.93)$ & $3.92(.97)$ & $4.00(1.06)$ & $4.79(1.06)$ & $2.71(1.16)$ & $2.75(1.19)$ \\
\hline No middle & 24 & $4.00(1.29)$ & $3.58(1.35)$ & $5.08(1.25)$ & $4.71(.91)$ & $2.38(1.06)$ & $1.96(.95)$ \\
\hline No end & 24 & $5.00(.93)$ & $4.00(.98)$ & $4.83(1.31)$ & $4.13(1.33)$ & $2.71(1.08)$ & $2.79(1.32)$ \\
\hline
\end{tabular}

${ }^{\text {a }}$ Absolute range, 1-6

$p<.001, \eta_{\mathrm{p}}^{2}=.33$, sex of the rater, $\Lambda=.85, F(6,90)=2.66$, $p=.02, \eta_{\mathrm{p}}^{2}=.15$, and an interaction between script terminus and proponent, $\Lambda=.74, F(12,180)=2.41, p=.006, \eta_{\mathrm{p}}^{2}=.14$, and, among relational context, proponent and sex of the rater, $\Lambda=.83, F(6,90)=3.10, p=.008, \eta_{\mathrm{p}}^{2}=.17$, on characteristics and future of the relationship.

Table 5 shows the mean ratings and $S D$ s of the characteristics and future of the relationship as a function of the main effects and significant interactions of relational context, communication strategy, script terminus, proponent gender, and rater's sex (second analysis).
Univariate analyses showed that relational context contributed to the expectation that the relationship would continue, $F(1$, $95)=68.68, p<.001, \eta_{\mathrm{p}}^{2}=.42$, and, as in the first analysis, it was associated with a stable relationship. The sex of the rater affected the inferred probability of sexual intercourse, $F(1$, $95)=7.18, p=.009, \eta_{\mathrm{p}}^{2}=.07$, as men had higher expectations that the encounter would lead to sexual intercourse than women. A significant interaction between script terminus and proponent also affected this encounter's characteristics, $F(2,95)=11.67$, $p<.001, \eta_{\mathrm{p}}^{2}=.20$, and showed a lower inferred probability of sexual intercourse when the condom was proposed at the
479

480 481 482 483 484 485 486 487 488 489

\begin{tabular}{|l|lll|} 
Journal $:$ Large 10508 & Dispatch : 8-1-2011 & Pages : 11 \\
Article No. : 9725 & $\square$ LE & $\square$ TYPESET \\
MS Code: ALVAREZ_1-3 & $\sim_{\text {CP }}$ & $\checkmark$ DISK \\
\hline
\end{tabular}


Table 5 Mean scores and $S D$ s for main effects and significant interactions for characteristics and future of the relationship (second analysis)

\begin{tabular}{|c|c|c|c|c|c|c|c|}
\hline Controlled variables & $n$ & $\begin{array}{l}\text { Emotional proximity } \\
M(S D)\end{array}$ & $\begin{array}{l}\text { Relationship continuation }{ }^{\mathrm{a}} \\
M(S D)\end{array}$ & $\begin{array}{l}\text { Sexual relations }{ }^{\mathrm{a}} \\
M(S D)\end{array}$ & $\begin{array}{l}\text { Condom use }{ }^{\mathrm{a}} \\
M(S D)\end{array}$ & $\begin{array}{l}\mathrm{STI}^{\mathrm{a}} \\
M(S D)\end{array}$ & $\begin{array}{l}\mathrm{HIV}^{\mathrm{a}} \\
M(S D)\end{array}$ \\
\hline \multicolumn{8}{|c|}{ Relational context (RC) } \\
\hline Stable & 72 & $4.67(.90)$ & $4.43(.95)$ & $4.60(1.31)$ & $5.07(1.29)$ & $2.79(.99)$ & $2.61(1.11)$ \\
\hline Casual & 72 & $3.55(1.35)$ & $3.11(.94)$ & $4.69(1.59)$ & $5.08(1.24)$ & $2.97(1.06)$ & $2.93(1.08)$ \\
\hline \multicolumn{8}{|c|}{ Communication strategy } \\
\hline Verbal & 72 & $4.00(1.23)$ & $3.72(1.18)$ & $4.75(1.38)$ & $5.10(1.18)$ & $2.89(.99)$ & $2.75(1.07)$ \\
\hline Non-verbal & 72 & $4.23(1.31)$ & $3.82(1.13)$ & $4.51(1.52)$ & $5.06(1.35)$ & $2.88(1.07)$ & $2.79(1.14)$ \\
\hline \multicolumn{8}{|l|}{ Script terminus (ST) } \\
\hline Beginning & 48 & $3.88(1.18)$ & $3.65(1.04)$ & $3.83(1.72)$ & $4.69(1.57)$ & $2.92(1.01)$ & $2.90(1.13)$ \\
\hline Middle & 48 & $4.21(1.16)$ & $4.02(1.10)$ & $5.02(.96)$ & $5.35(.86)$ & $2.85(1.07)$ & $2.69(.99)$ \\
\hline End & 48 & $4.25(1.45)$ & $3.65(1.28)$ & $5.04(1.25)$ & $5.19(1.18)$ & $2.88(1.02)$ & $2.73(1.18)$ \\
\hline \multicolumn{8}{|l|}{ Proponent $(\mathrm{P})$} \\
\hline Woman (w) & 72 & $4.20(1.23)$ & $3.81(1.11)$ & $5.22(.89)$ & $5.22(.94)$ & $2.85(1.00)$ & $2.69(1.08)$ \\
\hline $\operatorname{Man}(m)$ & 72 & $4.03(1.32)$ & $3.74(1.20)$ & $4.04(1.66)$ & $4.93(1.51)$ & $2.92(1.06)$ & $2.85(1.12)$ \\
\hline \multicolumn{8}{|l|}{ Sex rater $(S)$} \\
\hline Woman & 72 & $4.07(1.31)$ & $3.81(1.11)$ & $4.39(1.57)$ & $4.88(1.39)$ & $3.07(1.07)$ & $2.92(1.10)$ \\
\hline Man & 72 & $4.15(1.24)$ & $3.74(1.20)$ & $4.88(1.29)$ & $5.28(1.10)$ & $2.69(.96)$ & $2.63(1.09)$ \\
\hline \multicolumn{8}{|l|}{$\mathrm{ST} \times \mathrm{P}$} \\
\hline Begin woman & 24 & $4.13(1.19)$ & $3.83(.92)$ & $5.04(1.04)$ & $5.29(.91)$ & $2.96(1.12)$ & $2.75(1.15)$ \\
\hline Begin man & 24 & $3.63(1.13)$ & $3.46(1.14)$ & $2.63(1.38)$ & $4.08(1.86)$ & $2.88(.90)$ & $3.04(1.12)$ \\
\hline Middle woman & 24 & $4.17(1.11)$ & $4.00(1.15)$ & $5.29(.75)$ & $5.21(.78)$ & $2.79(.88)$ & $2.50(.88)$ \\
\hline Middle man & 24 & $4.25(1.22)$ & $4.04(1.08)$ & $4.75(1.07)$ & $5.50(.93)$ & $2.92(1.25)$ & $2.89(1.08)$ \\
\hline End woman & 24 & $4.29(1.40)$ & $3.58(1.25)$ & $5.33(.87)$ & $5.17(1.13)$ & $2.79(1.02)$ & $2.83(1.20)$ \\
\hline End man & 24 & $4.21(1.53)$ & $3.71(1.33)$ & $4.75(1.51)$ & $5.21(1.25)$ & $2.96(1.04)$ & $2.63(1.17)$ \\
\hline
\end{tabular}

$\mathrm{RC} \times \mathrm{P} \times \mathrm{S}$ is a significant interaction and it is shown in Fig. 2 for better understanding of the interaction

a Absolute range, 1-6

490 beginning of the encounter by a man. For condom use expec491 tation, there was an interaction and, both in stable and casual 492 relationships, the woman proponent increased the expectations 493 that the condom would be used, although for men this occurred 494 more in stable relationships and for women in casual relation495 496 497 498 ships, $F(1,95)=10.28, p=.002, \eta_{\mathrm{p}}^{2}=.10$ (Fig. 2 ).

Finally, the sex of the rater affected STI expectations, as women associated condom proposal with the presence of an STI more than men, $F(1,95)=5.64, p=.02, \eta_{\mathrm{p}}^{2}=.06$.

\section{Discussion}

Findings confirmed the possibility of impression formation on personality traits and the development of expectations towards the characteristics and future of the relationships based on the manipulated variables in the sexual encounter descriptions.

Particular emphasis has been given to romanticism in this discussion, not because we defend that it should always be present in sexual encounters, but due to the fact that its
499

500

501

502

503

504

505

506
Fig. 2 Interaction among relational context, proponent, and sex of the rater in expectations of condom use
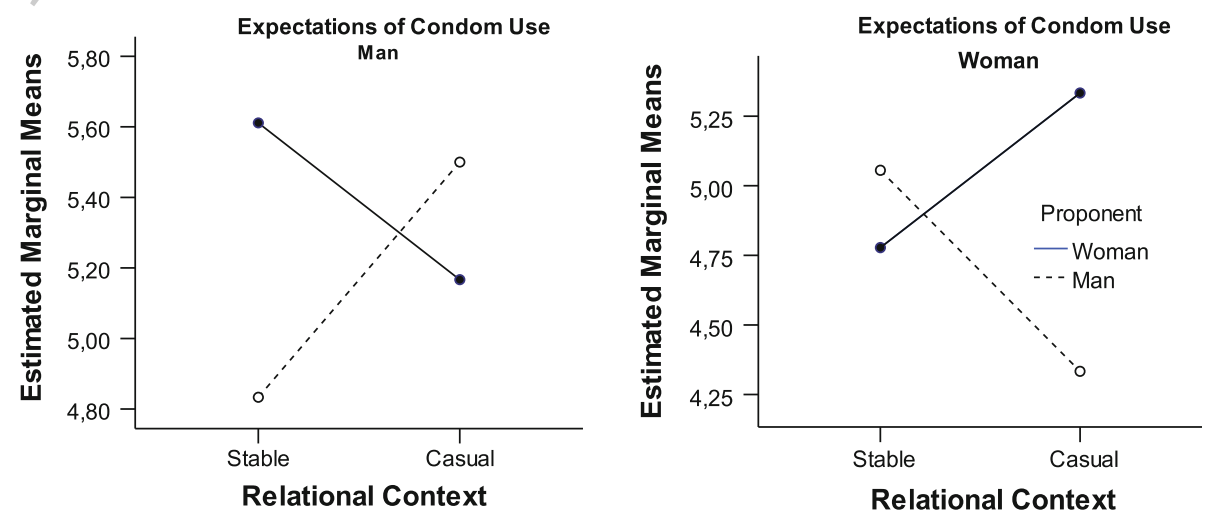

Relational Context

\begin{tabular}{|l|lll|}
\hline Journal $:$ Large 10508 & Dispatch : 8-1-2011 & Pages : 11 \\
Article No. : 9725 & $\square$ LE & $\square$ TYPESET \\
MS Code : ALVAREZ_1-3 & $\sim_{\text {CP }}$ & $\checkmark$ DISK \\
\hline
\end{tabular}


association with the condom increased the likelihood of its usage (e.g., Galligan \& Terry, 1993).

The relational context only partially affected partner perception and had a low impact on condom use expectations. Partners in a stable relationship were viewed as being more responsible but not as more romantic as predicted in Hypothesis 1. Thus, it was only partially corroborated. This lack of differentiation in perceived romanticism alerts us to the possibility of it being equally present in casual relationships, thus making the latter more legitimate. Furthermore, contrary to what was expected, condom use was not lower in a stable relationship than in a casual one, and there did not seem to be a connection between sex as an expression of desire and protection or between sex as an expression of love and the absence of protection (Rosenthal et al., 1998). This was not the result of affection also being associated with protection, but of the desire to not have a connection with condom use, hence not corroborating Hypothesis 6 .

Another conclusion of this study is that condom use was not viewed as being romantic, which corroborated Hypothesis 2 . Indeed, the partners who did not use a condom in a sexual encounter were perceived as being more romantic, even though those who did use it were considered to be more responsible. However, romanticism is believed to be more valued in an encounter than responsibility, since it is an actively sought expectation associated with sexual encounters (Flowers et al., 1997; Galligan \& Terry, 1993) and considered more important than other social traits (Bryan et al., 1999). Therefore, it is believed that by not using protection, a message of greater affection, intimacy, and expectations of commitment associated with the encounter may be transmitted. The fact that emotional proximity was coupled with encounters excluding condom use, partially corroborating Hypothesis 5, helps to uphold the symbolic barrier between trust and intimacy conveyed by the condom (Hammer et al., 1996). Belief in the fear of causing a negative impression by using the condom may be justified in terms of less romanticism being associated with the condom proponent.

However, it is possible to increase the perception of romanticism and the expectation of sexual intercourse in encounters where the condom is used, when suggested by the woman, introduced later on in the encounter and verbally referred to. When the probability of condom use was analyzed in an encounter, the most effective proponent was, invariably, the woman. This result did not corroborate the fear of women of being socially stigmatized for suggesting and being in possession of a condom, thus not corroborating Hypothesis 3 . Whenever a man suggested condom use, it was more effective in accentuating romanticism and responsibility halfway through the encounter, hence corroborating Hypothesis 4, which anticipated the end of the sexual encounter as the less intrusive moment for condom introduction. Perceived romanticism was increased when the condom was verbally referred to. As far as romanticism is concerned, non-verbal condom proposal at the beginning of an encounter by a man should be carefully considered. As for expectations regarding sexual intercourse, condom introduction instigated by a man at the beginning of an encounter should also be equally considered. So, women can be encouraged to suggest condom use, since being regarded as more romantic may increase acceptance and use of protection, contrary to what women habitually fear. These results may reflect the determinant role of the woman in sexual encounters, as on showing herself to be responsible in terms of protection she is also giving information as to her availability to have sex, thus increasing the positive expectations of a set of characteristics regarding the relationship and the proponent's personality traits. However, men should also be encouraged, and try to avoid premature condom proposal in sexual relationships, since it may lead to the understanding that sexual intercourse has been taken for granted from an early stage, thus altering the expectations of the determinant female role in such situations, which is not well accepted by either gender.

Therefore, in order to increase the probability of condom acceptance and to have protected sexual intercourse, the condom should be introduced later on in the sexual encounter. This recommendation differs from most, although it has been identified in other studies (e.g., Edgar \& Fitzpatrick, 1993), suggesting that additional research is necessary to test its benefits.

Condom reference (verbal and non-verbal) during the encounter increased expectations that it would be used. This may indicate that once protection has been addressed or brought to the aware ness of the partners during an encounter, it will be more difficult to forget its importance and get around using it. An educational approach to promoting the development of competencies for negotiating the condom may be a way of heightening its use (Visser \& Smith, 2001) and condom reference during the sexual encounter draws on the most effective strategies for doing so.

Verbal reference to the condom deserves mention, especially when instigated by the man, since it triggered a positive impression of the partner and, consequently, tends to bring about a more positive reaction in the receiver (Snyder, Tanke, \& Berscheid, 1977). In fact, women associated more empathy towards their thoughts and feelings to verbal proposals (Bryan et al., 1999), and this communication strategy may contribute to the transmission of greater proximity and increase the use of a type of protection that is often considered the antagonist of intimacy. Nevertheless, the communication strategy does not seem to contain information on expectations regarding the characteristics and future of the relationship and thus both the verbal and non-verbal form can indistinctly affect condom introduction in a sexual encounter.

A more preoccupying conclusion is that condom use indicates STIs. It is not the first time that condom use has been associated with promiscuity on the part of university students (Williams et al., 1992). The condom does not seem to be associated with an act of protection, but rather with an act of remediation, particularly for the women in the sample. This 
belief may be taken as an indication that condom use is limited to a sporadic and transitory situation, such as the case of a STI. However, a more positive interpretation of the data may show that protection is frequent in the case of a STI. Nevertheless, there seems to be a relationship between condom use and disease, instead of the condom being associated with a healthy status.

There are a number of limitations in this study which need to be addressed. First of all, as a convenience sample, the findings cannot be generalized to cover other age groups from different geographical regions or with different sociocultural backgrounds. Secondly, artificially created situations do not guarantee similarity to the actual experience itself. In spite of the fact that these situations were constructed to be as close as possible to the sequence of expected events in the sexual experiences, we are aware of how difficult it is to create a realistic environment. The use of filmed sequences would have helped render the encounters more real. Thirdly, due to the study design, the lack of significance of some outcomes may be due to the small power associated with the reduced sample size in some experimental conditions. However, the significant relations encountered among many of the manipulated variables encouraged us to present this study, although additional participants would be necessary to fully evaluate its outcomes and help to clarify some of the current results.

The most important implication of this study is the need to make condom use and its proponent more romantic. The condom should convey a sense of concern and affability towards one's partner, and protection should be connected to affection and not disease, contrary to what seems to be the association shared by the sample, particularly the women.

We may also highlight the importance of women being encouraged to take the lead in suggesting condom use, owing to the higher level of romanticism and positive characteristics associated with this situation. We realize that women, in general, are already disproportionately overburdened with having to accommodate so many sides to heterosexual relations, such as avoiding unwanted pregnancies, greater physical vulnerability, STIs, and sexual violence that to ask them to take on the extra responsibility of condom use may not be the fairest and most acceptable strategy. ${ }^{3}$ However, it is possible to regard our suggestion from a more positive perspective, whereby women do not have to wait for a man to make the first move and, indeed, feel perfectly at ease to take the lead themselves, whenever so desired. Hence, this approach may be viewed as a way of empowering women rather than burdening them. Even so, in the case of men, a number of alternatives for increasing romanticism and thus the likelihood of condom use have emerged. We encourage the suggestion of condom use halfway through the

\footnotetext{
3 We would like to thank an anonymous reviewer for drawing attention to this fact.
}

sexual encounter, at which point stronger physical intimacy will not yet have occurred. Another important implication is the verbal introduction of the condom as a strategy for making its use known and creating more positive impressions of the proponent. Finally, as mentioning the condom during the sexual encounter increases expectations of its use, it is thought that reference to the condom may heighten the probability that it will be used during sexual intercourse.

Future research may include interventions planned in accordance with the results obtained, so as to enable testing of the relevance of the findings in this study, particularly the reference to condom use halfway through the sexual encounter, which clearly calls for further research.

\section{Appendix}

Example of one experimental condition for casual relationships (condom use, verbal communication strategy, by a man proponent, up to the end of the script):

Carlos and Ana do not know each other and, on this particular day, they meet in a disco. They notice each other and look each other in the eye. He starts to chat to her and they talk for a while about trivial things and pay each other compliments before approaching more personal subjects. In the disco, they have a few drinks, they chat and try to get to know each other better, and they are physically attracted. They dance and/ start to touch each other/. They kiss and continue to kiss and then they both decide to leave. Their caresses become more intimate and they decide to go to one of their homes. They listen to music, dim the lights, and begin to kiss and exchange caresses again. They get completely undressed. He says he prefers using a condom.

\section{References}

Alferes, V. R. (1997). Encenaçôes e comportamentos sexuais: Para uma psicologia social da sexualidade [Scenarios and sexual behaviors: For a social psychology of sexuality]. Porto: Edições Afrontamento.

Alvarez, M. J. (2005). Representaçôes cognitivas e comportamentos sexuais de risco: $O$ guião e as teorias implícitas da personalidade nos comportamentos de protecção sexual [Cognitive representations and sexual risk behaviors: The script and the implicit personality theories in sexual protective behaviors]. Lisboa: FCG/FCT.

Alvarez, M. J., \& Garcia-Marques, L. (2008). Condom inclusion in cognitive representations of sexual encounters. Journal of Sex Research, 45, 358-370.

Applebaum, M., \& McCall, R. (1983). Design and analysis in developmental psychology. In P. Mussen (Ed.), Handbook of child psychology: Vol. 1. History, theory, and methods (pp. 415476). New York: Willey.

Bruner, J. S., \& Tagiuri, R. (1954). The perception of people. In G. Lindzey (Ed.), Handbook of social psychology (pp. 634-654). Cambridge, MA: Addison-Wesley.

$\begin{array}{lll}\text { Journal }: \text { Large 10508 } & \text { Dispatch : 8-1-2011 } & \text { Pages : 11 } \\ \text { Article No. : 9725 } & \square \text { LE } & \square \text { TYPESET } \\ \text { MS Code : ALVAREZ_1-3 } & \sim_{\text {CP }} & \checkmark \text { DISK }\end{array}$


Bryan, A. D., Aiken, L. S., \& West, S. G. (1999). The impact of males proposing condom use on perceptions of an initial sexual encounter. Personality and Social Psychology Bulletin, 25, 275-286.

Civic, D. (1999). The association between characteristics of dating relationships and condom use among heterosexual young adults. AIDS Education and Prevention, 11, 343-352.

Cline, R. J., Johnson, S. J., \& Freeman, K. E. (1992). Talk among sexual partners about AIDS: Interpersonal communication for risk reduction or risk enhancement? Health Communication, 4, 39-56.

Conley, T., \& Rabinowitz, J. (2004). Scripts, close relationships and, symbolic meanings of contraceptives. Personal Relationships, 11, $539-558$

Edgar, T., \& Fitzpatrick, M. A. (1993). Expectations for sexual interaction: A cognitive test of the sequencing of sexual communication behavior. Health Communication, 5, 239-261.

Flowers, P., Smith, J. A., Sheeran, P., \& Beail, N. (1997). Health and romance: Understanding unprotected sex in relationships between gay men. British Journal of Health Psychology, 2, 73-86.

Galambos, J. A., Abelson, R. P., \& Black, J. B. (1986). Knowledge structures. Hillsdale, NJ: Lawrence Erlbaum.

Galligan, R. F., \& Terry, D. J. (1993). Romantic ideals, fear of negative implications, and the practice of safe sex. Journal of Applied Social Psychology, 23, 1685-1711.

Hamilton, D. (1986). Person perception. In L. Berkowitz (Ed.), A survey of social psychology (3rd ed., pp. 136-162). New York: Holt, Rinehart \& Winston.

Hammer, J. C., Fisher, J. D., Fitzgerald, P., \& Fisher, W. A. (1996). When two heads aren't better than one: AIDS risk behavior in college-age couples. Journal of Applied Social Psychology, 26, 375-397.

Hynie, M., \& Lydon, J. E. (1995). Women's perceptions of female contraceptive behavior: Experimental evidence of the sexual double standard. Psychology of Women Quarterly, 19, 563-581.

Maticka-Tyndale, E. (1991). Sexual scripts and AIDS prevention: Variations in adherence to safer-sex guidelines by heterosexual adolescents. Journal of Sex Research, 28, 45-66.
McKinney, K., Sprecher, S., \& Orbuch, T. (1987). A person perception experiment examining the effects of contraceptive behavior on first impressions. Basic and Applied Social Psychology, 8, 235-248.

Miller, L. C., Bettencourt, B. A., DeBro, S. C., \& Hoffman, V. (1993). Negotiating safer sex: Interpersonal dynamics. In J. Pryor \& G. Reeder (Eds.), The social psychology of HIV infection (pp. 85123). Hillsdale, NJ: Lawrence Erlbaum.

Misovich, S. J., Fisher, J. D., \& Fisher, W. A. (1996). The perceived AIDS-preventive utility of knowing one's partner well: A public health dictum and individuals' risky sexual behavior. Canadian Journal of Human Sexuality, 5, 83-90.

Misovich, S. J., Fisher, J. D., \& Fisher, W. A. (1997). Close relationships and elevated HIV risk behavior evidence and possible underlying psychological processes. Review of General Psychology, 1, 72-107.

Rosenberg, S., \& Sedlak, A. (1972). Structural representations of implicit personality theory. In L. Berkowitz (Ed.), Advances in experimental social psychology (pp. 235-297). New York: Academic.

Rosenthal, D., Gifford, S., \& Moore, S. (1998). Safe sex or safe love: Competing discourses? AIDS Care, 10, 35-47.

Sacco, W., Rickman, R., Thompson, K., Levine, B., \& Reed, D. (1993). Gender differences in AIDS-relevant condom attitudes and condom use. AIDS Education and Prevention, 5, 311-326.

Schneider, D. J. (1973). Implicit personality theory: A review. Psychological Bulletin, 79, 294-309.

Snyder, M., Tanke, E., \& Berscheid, E. (1977). Social perception and interpersonal behavior: On the self-fulfilling nature of social stereotypes. Journal of Personality and Social Psychology, 35, 656-666.

Visser, R., \& Smith, A. (2001). Relationship between sexual partners influences rates and correlates of condom use. AIDS Education and Prevention, 13, 413-427.

Williams, S. S., Kimble, D. L., Covell, N. H., Weiss, L. H., Newton, K. J., Fisher, J. D., \& Fisher, W. A. (1992). College students use implicit personality theory instead of safer sex. Journal of Applied Social Psychology, 22, 921-933.

\begin{tabular}{|l|lll|} 
Journal $:$ Large $\mathbf{1 0 5 0 8}$ & Dispatch : 8-1-2011 & Pages : $\mathbf{1 1}$ \\
Article No. : 9725 & $\square$ LE & $\square$ TYPESET \\
MS Code : ALVAREZ_1-3 & $\sim$ CP & $\checkmark$ DISK \\
\hline
\end{tabular}

